\title{
Experimental Study on Recycled Concrete Aggregates with Rice Husk Ash as Partial Cement Replacement
}

\author{
Naraindas Bheel ${ }^{a^{*}}$, Shanker Lal Meghwar a, Samiullah Sohu ${ }^{b}$, Ali Raza Khoso ${ }^{\text {a }}$, \\ Ashok Kumar ${ }^{\mathrm{c}}$, Zubair Hussain Shaikh ${ }^{\mathrm{a}}$ \\ ${ }^{a}$ Department of Civil Engineering, Mehran University of Engineering \& Technology, Jamshoro 76062, Pakistan. \\ ${ }^{b}$ Department of Civil Engineering, Quaid-E-Awam University College of Engineering Science \& Technology, Larkana 77150, Pakistan. \\ ${ }^{c}$ Department of Civil Engineering, Swedish College of Engineering Science \& Technology, Rahim Yar Khan 64200, Pakistan .
}

Received 08 July 2018; Accepted 02 October 2018

\begin{abstract}
Concrete is highly utilized construction material around the globe and responsible for high depreciation of the raw materials. Consumption of this material in construction industry is arching upward day by day. On the other hand, debris of demolished concrete structures are being dumped as waste. For developing countries such waste is not a good sign and need its proper utilization by recycling it into useful product. In this consequence, this study is an attempt to utilize demolished waste concrete by converting into coarse aggregates. This research was conducted on recycled cement concrete aggregates of demolished structures and Rice Husk Ash (RHA). The purpose of this experimental study is to analyze the mechanical properties of concrete; when cement is partially replaced with RHA and natural aggregates by recycled aggregates (RA). In this study, the cement was replaced by RHA up to $10 \%$ by weight of cement. For experimental purpose, total 135 concrete specimens were prepared, cured and tested in Universal Testing Machine (UTM). Finally, laboratory results were compared in terms of compressive and splitting tensile strength made with normal and recycled coarse aggregates. All the specimens were prepared at 1:1.5:3 with $0.50 \mathrm{w} / \mathrm{c}$ ratio and tested at $7,14,21,28$ and 56 days curing ages. It is observed from experimental analysis that the workability of fresh normal concrete is $7 \%$ and $10 \%$ greater than recycled aggregates concrete blended with $10 \%$ RHA and only recycled aggregates concrete without RHA respectively. The compressive strength increases up to $6 \%$, whilst splitting tensile strength increases $4 \%$ at 56 days curing, when the cement is replaced $10 \%$ by RHA. It is, further, concluded that with more than $10 \%$ RHA replacement with cement, the compressive strength decreases. This study would help the construction experts to use such wasted concrete into useable production of new concrete projects.
\end{abstract}

Keywords: Rice Husk Ash (RHA); Recycled Aggregate (RA); Cement Replacement; Concrete.

\section{Introduction}

The latest development has inflicted severe damages on the environment and had endangered its sustainability [1]. The exploitation of natural resources, in particular non-renewable resources, for construction purposes leads to millions of tons of construction and demolition waste every year. The increasing demand of concrete in the world is a red sign for the natural deposits. The coarse aggregate is a major part of concrete containing two third of its whole mass. The latest research has proved that there are several mechanism to produce recycled coarse aggregates (RCA) to save upcoming material crises threat. Recycled concrete aggregates are generally made of liberated natural coarse aggregate

* Corresponding author: naraindas04@gmail.com

dol http://dx.doi.org/10.28991/cej-03091160

$>$ This is an open access article under the CC-BY license (https://creativecommons.org/licenses/by/4.0/).

(C) Authors retain all copyrights. 
and the physical properties of these aggregates are much difference than natural coarse aggregate [2].

Several structures in the history got destructed due to many reasons and producing massive masses of waste. Mostly these demolished materials are sent to landfill instead of being reused and recycled in new construction.

In major cities of the world there is a surge in construction and demolition waste quantities causes an adverse effect on the environment [4]. The re-utilizing of recycled aggregate and concrete specimens is a significant idea to resolve the issue of managing of construction and demolition waste [5]. The construction work exploits 50\% raw material, $40 \%$ of total energy, as well as generates $50 \%$ of total waste [6]. Only the USA is producing 123 million tons per year construction waste from buildings. On the other side, due to increase in construction activities, the global demand for aggregates exceed 26.8 billion tons per year [7]. The total amount of waste generated in the European Union in 2010 was over 2.5 billion tones, of which almost $35 \%$ ( 860 million tons) derived from construction and demolition activities [8]. By looking the huge demand of aggregates and on other hand the waste generated from demolition, the experts are extremely worried concern about recycling of waste to move towards sustainable growth. This use of waste material as recycled aggregate in concrete can be a useful for both environmental and economic aspects in the construction work.

Huge number of studies are available on RCA with different concepts. The use of recycled concrete aggregate is an application for making sand lime brick in Kuwait is practiced for years [9, 10]. Many researchers conducted an experimental work on the characteristics properties of RCA; mainly focused in the relationship between the elastic modulus and compressive strength of re-used concrete such as [11-13]. A comprehensive laboratory study on recycled aggregates include; compressive strength, flexural strength, splitting tensile strength, elastic modulus, drying shrinkage, workability, and water absorption was carried out by Ozbakkaloglu et al. (2018). The studies concludes that elasticity increase with increase in size of aggregates and on the other hand splitting tensile strength and flexural strength reduces. There was overall reduction in mechanical properties of concrete, showing slighter inferiority of recycled aggregates [13].

According to Jianzhuang Xiaoa et al. [14], the compressive strength of recycled aggregate concrete specimens decreases with increasing recycled aggregate. When the recycled aggregate replaced to $100 \%$ then the elastic modulus is reduced by $45 \%$. The compressive strength of concrete prepared with recycled aggregates is about $22 \%-32 \%$ less than the normal concrete, prepared with fresh aggregates [15]. Tam et al. (2008) conducted a study on recycled aggregates obtained from ten different sites. He found that the properties of recycled aggregates significantly vary, and compressive strength of concrete prepared from those aggregates is generally varies from 50 to $63 \mathrm{MPa}$ [16] .The effect of coarse aggregates' size on the concrete strength was investigated by Ma Kang and LiWeibin recently in 2018, where different aggregates sizes effects were noted on recycled concrete. The study concludes that the size of aggregates has important part in strength parameter, the higher compressive strength was increased with increasing size of aggregates [3]. The effect of lightweight recycled aggregates produced from waste and adding supplementary cementitious material (fly ash and metakaolin) was studied by Luki'c et al (2016) [5].

Mostly studies suggest that the recycled aggregates has no significant impact on compressive strength, hence, mostly recycled aggregates used for non-structural purposes. However, an attempt to use recycled aggregates to sustain higher loading was carried out in Australia by Xie and Ozbakkaloglu (2015) on concrete filled FRP tubes. The study found that the increase in RCA increase the ultimate axial strain, reduces the hoop rupture but reduces the compressive strength [11]. Also, small effect of RCA was found on strand bond strength in pre stressed concrete [27]. Beside the recycled aggregates, several industrial and agricultural waste are becoming part of concrete such as fly ash, blast, metakaolin, furnace slag and rice husk.

This study decided to use Rice Husk Ash as supplementary material in concrete to replace cement. Rice covers $1 \%$ of earth's surface and is a primary source of food for billions of people [17]. The rice husk ash obtained from rice paddy is a mineral admixture for concrete and RHA considered as cementitious material [18]. A report published in 2014-15 claims that the utilization of rice in world is 500.5 million tonnes [19]. This ash contains 90 to $95 \%$ silica $\left(\mathrm{SiO}_{2}\right), 1-3 \%$ $\mathrm{K}_{2} \mathrm{O}$ and less than $5 \%$ unburned carbon. It is highly porous and lightweight material with large external surface area [20]. RHA is produced from burning rice husk at temperature of $600^{\circ} \mathrm{C}$ to $700^{\circ} \mathrm{C}$. It contains silica which undergoes structural transformations depending on the temperature regime during combustion. Amorphous silica is found at $550^{\circ} \mathrm{C}$ $-800^{\circ} \mathrm{C}$ and crystalline silica is formed at greater temperature [21]. The particle size of RHA is finer than the particle size of OPC which improves the properties of concrete [22]. RHA when combine with lime in the presence of water, forms a stable and more amorphous hydrate (calcium silicate). This hydrate is stronger, less permeable and more resistant to chemical attack.

Many researches are carried out on utilizing of industrial waste/agricultural waste such as fly ash, corn cob ash, metakaolin, bagasse ash and RHA during past two decades such as [23-26]. Rice Husk is also utilised in clay to increase the unconfined compressive strength. In this regard, Jongpradist et.al, (2018) recently did an experimental study on rice husk as cementations material i.e. partially replacement of cement. The study founds interesting results after mixing RHA in clay with cement. The results suggest that favourable results could be obtained by adding $35 \%$ RHA and $10 \%$ 
cement in clay [26]. The partial replacement of cement by Rice Husk was also studied by other authors such as Bhusan R. et.al (2017). To study this effect, compressive, flexural and splitting tensile strength test were performed in laboratory on masonry blocks. The study found that to some extend the increment in strength found by adding rice husk up to $10 \%$ [28]. According to M. P. Kumar (2003), rice husk ash improves the workability, strength and durability of concrete [29]. It has many applications in concrete such as it is an ideal additive to reduce corrosion and to increase durability of concrete members [30]. It is very highly reactive and possesses pozzolanic properties [31]. Various researches utilized the RHA in the production of high-performance and high-durable concretes such as [32, 33]. The European Union Directive No. 2008/98/CE [34] encourages the reuse and recycling of waste materials. It is expected that by 2020 new building structures will include at least $5 \%$ of recycled materials.

In the majority of the concrete design codes and standards [e.g., ACI 318 (ACI 2011), AS 3600 (AS 2009), Eurocode (BSI 2004)], the compressive strength is the key indicator of concrete's mechanical properties. This is used to predict the other mechanical properties (i.e., splitting tensile strength, modulus of elasticity and flexural strength etc.). Hence the focus of this study is made over the compressive strength of recycled concrete. In addition to this splitting tensile strength was also studied. Also, in Pakistan, now a day, the use of aggregate in infrastructure and construction work development is at its peak. The construction sector has been boosted specially after inclusion of China Pakistan Economic Corridor projects. The higher authorities in this regard looking for research studies that could trigger them to use such recycled material to make the projects sustainable. The use of such recycled aggregate with supplementary materials could be used in construction work for economical purpose and further it can reduce the environmental degradation. This investigation is an attempt to replace natural coarse aggregate (NA) with recycled concrete aggregate (RCA) in structural concrete. Rice Husk Ash used in the present experimental study was obtained from suburb of Larkana. RCA produced by two-stage crushing of demolished concrete, and by further screening and removal of impurities such as reinforcement, paper, wood, plastics etc. Such type of concrete which made with recycled concrete aggregate is known as recycled aggregate concrete (RAC).

\subsection{Recycled Aggregate (RA)}

Recycled aggregates are obtained through a recycling process of concrete structures. The structural members like beam, column, footing etc of structure are the primary source of RA. When the demolition concrete passes through a screening and crushing process, these aggregates are produced. Mostly, RAs are extracted from waste concrete such as rejected pre-cast concrete members, broken masonry, road pavement, dismantled structures, left over ready mix concrete plant and the waste generated from concrete testing laboratories. Further, there are several other kinds of RA such as glass aggregates, brick aggregates, bitumen and asphalt aggregates, tiles and marbles recycled from flooring, concrete aggregates, and finishes and ceramic products aggregates. Typically, the aggregates obtained through processing of crushing of parent concrete i.e. demolished waste concrete is called Recycled Concrete Aggregates. These aggregates were initially obtained from unbound sub base materials like pavements. After World War II, these were started obtaining from building wastes in Europe [35, 36].

\section{Research Methodology}

Numerous experimental studies had been conducted by different researchers to analyse the different properties of concrete prepared with recycled aggregates. However, this study is an attempt in same queue of research and in addition to it, the rice husk ash (RHA) was included. The purpose of RHA is to add cementitious properties in concrete and to further increase the strength. This extensive experimental study is worked out to check the compressive and tensile strength of concrete specimens when natural aggregates concrete is replaced with recycled concrete aggregates and cement is replaced by RHA up to $10 \%$ by weight of cement.

For this reason, debris or generated concrete waste (demolished beams, columns and lintels of buildings) were collected from a city, Larkana, Pakistan. Following step by step procedure were adopted to obtain RA.

- The obtained debris was dismantled, segregated and broken into small pieces with the help of a hammer.

- The dismantled waste material was brought to laboratory for further processing like preliminary testing.

- The 19.5, 12.5, 9.5 and $4.75 \mathrm{~mm}$ sieves were used for classification of recycled aggregates and to obtain the required grading of aggregates.

To evaluate basic properties of materials i.e. water absorption, specific gravity, setting time etc. standard testing procedures of ASTM and BS were adopted. A concrete mix 1:1.5:3 at 0.50 water-cement ratio, with and without RCA was prepared with $10 \%$ of RHA. For every batch of concrete, slump test was performed using slump cone apparatus to check the flowability/workability of concrete. Moreover, for analysing the harden properties of concrete, total 135 specimens, which includes cubes of 4" x 4" x 4" and cylinders of 4" x 8" size were caste whose detail is illustrated in Table 1. All specimens were tested in Universal Testing Machine (UTM) at 7, 14, 21, 28 and 56 days curing period. 
Table 1. Specimens detail

\begin{tabular}{ccccc}
\hline Specimens & Curing Ages & Plain Concrete & RCA & RCA + 10\% RHA \\
\hline & 7 days & 3 & 3 & 3 \\
Cylinders for Cylindrical & 14 days & 3 & 3 & 3 \\
compressive strength & 21 days & 3 & 3 & 3 \\
& 28 days & 3 & 3 & 3 \\
\hline Total & 56 days & 3 & 3 & 15 \\
\hline & 7 days & 15 & 3 & 3 \\
\hline Cylinders for Splitting & 14 days & 3 & 3 & 3 \\
tensile strength & 21 days & 3 & 3 & 3 \\
& 28 days & 3 & 3 & 3 \\
\hline Total & 56 days & 3 & 3 & 15 \\
\hline & & 15 & 15 & 3 \\
\hline Cubes for Cubical & 7 days & 3 & 3 & 3 \\
\hline Tompressive strength & 21 days & 3 & 3 & 3 \\
& 28 days & 3 & 3 & 3 \\
\hline & 56 days & 3 & 15 & 3 \\
\hline
\end{tabular}

\section{Materials}

\subsection{Rice Husk Ash (RHA)}

Rice Husk $(\mathrm{RH})$ is considered as waste stuff after separation of rice grains. Either it is dumped in agriculture field whereby it works as organic fertilizer, or it is dumped on open dumps where it takes years to decompose. For this study, $\mathrm{RH}$ is collected from surrounding of Larkana city and burnt in open air till it converts into ash. This raw ash is further sieved through sieve \#30 for removing any unwanted material from it and sieved ash as shown in Figure 1 is used in concrete manufacturing.

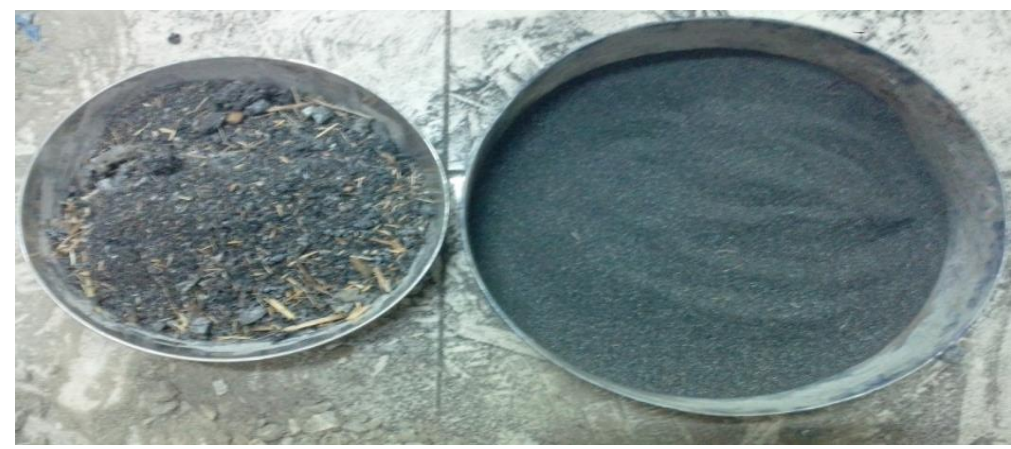

Figure 1. Rice husk ash before and after sieving

\subsection{Cement}

The ordinary Portland cement (OPC) was used as a binding material. The locally available brand name Lucky Cement is used. The preliminary properties of cement were investigated and found as: normal consistency $33 \%$, initial and final setting time 30 and 120 mints respectively.

\subsection{Fine, Coarse and Recycled Aggregates}

Hill sand is used as fine aggregate and crushed aggregates are used as coarse aggregates. Material properties were evaluated in laboratory for assuring the quality of materials. The physical properties are listed in Table 2 beside it, RCA is obtained as mentioned above through manually hammering of remaining's of demolished buildings. Large pieces of destroyed buildings like beams, columns, slab etc. were hammered manually into small pieces as shown in Figure 2 further, fine, normal coarse and recycled concrete aggregates are sieved through standard sieves to assure the size of aggregates, results are graphically shown in Figure 3 and 4 in addition to it different physical properties as illustrated in 
Table 3 were conducted on RCA before using in concrete.

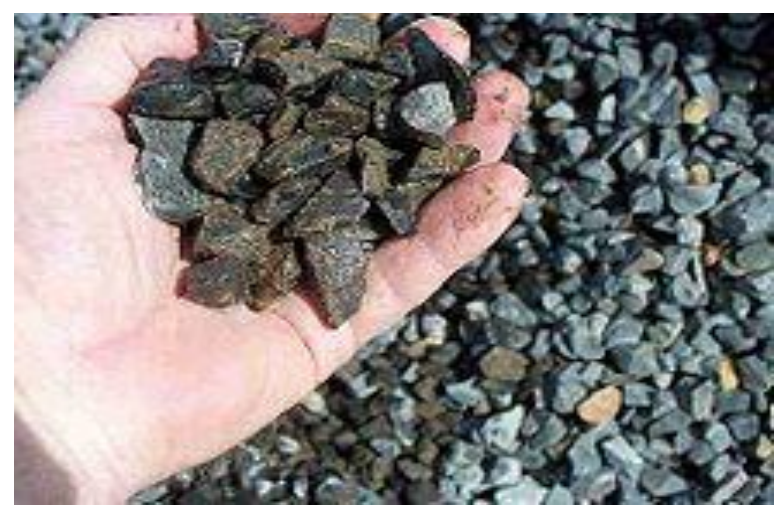

Figure 2. Recycled concrete aggregates after processing

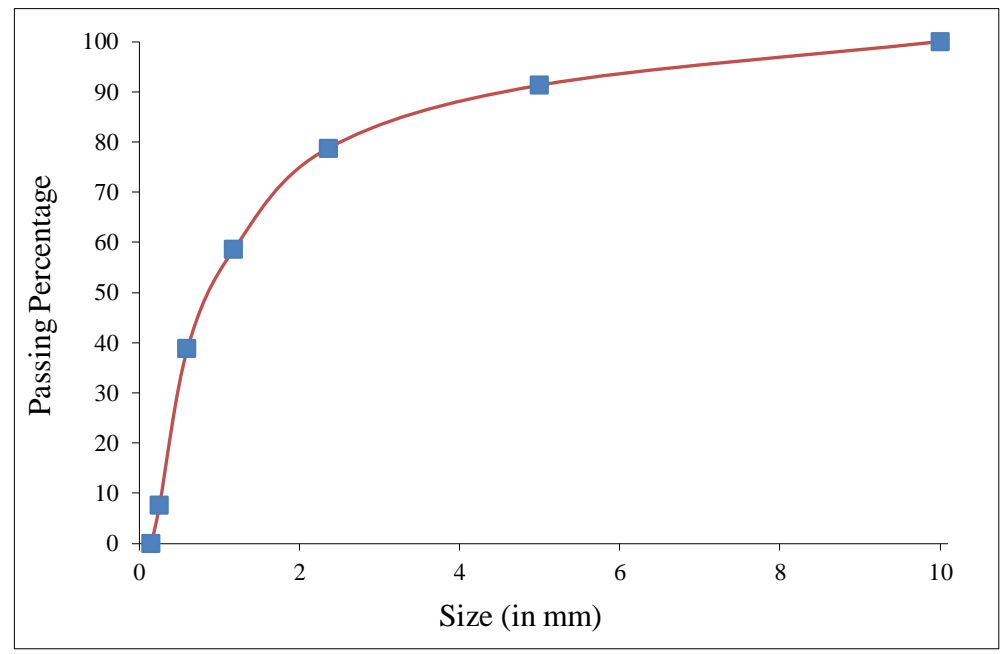

Figure 3. Sieve analysis results of fine aggregates

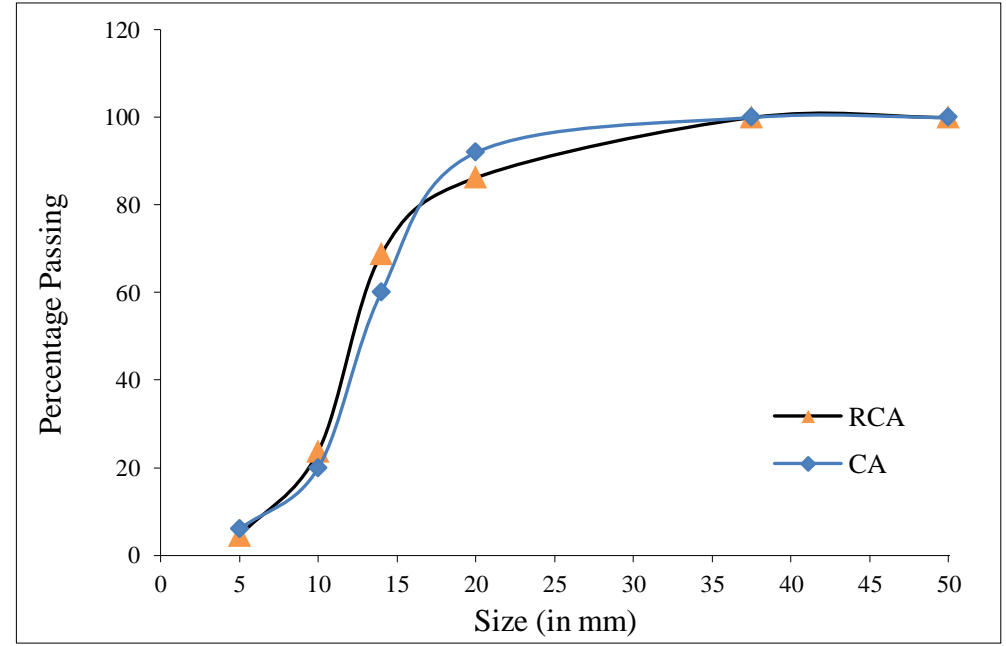

Figure 4. Sieve analysis results of normal (CA) and recycled concrete (RCA) aggregates

Table 2. Properties of fine and coarse aggregates

\begin{tabular}{cccc}
\hline Sr. No. & Properties & Fine Aggregates & Coarse Aggregates \\
\hline 01 & Fineness Modulus & 2.25 & -- \\
02 & Specific Gravity & 2.8 & 2.7 \\
03 & Water absorption & $3 \%$ & $1.5 \%$ \\
04 & Bulk density (compacted) & $119.981 \mathrm{~b} / \mathrm{ft}^{3}$ & $97.381 \mathrm{~b} / \mathrm{ft}^{3}$ \\
\hline
\end{tabular}


Table 3. Physical properties of RCA

\begin{tabular}{ccc}
\hline S. No & Physical Property & Result \\
\hline 01 & Size of aggregate & $20 \mathrm{~mm}$ \\
02 & Specific Gravity & 2.49 \\
03 & Water absorption & $2.33 \%$ \\
04 & Bulk Density (compacted) & $86.461 \mathrm{~b} / \mathrm{ft}^{3}$ \\
\hline
\end{tabular}

\section{Results and Discussion}

\subsection{Slump Test}

This test was conducted to measure the workability of concrete. Slump test was conducted on normal concrete and concrete with RC aggregates and 10\% of RHA. Results of slump test are tabulated in Table 4. It was observed that concrete with of RCA reduces workability of concrete up to $7.7 \%$, while workability plummeted to $11.5 \%$ when $10 \%$ of RHA is replaced with cement in addition of RCA in concrete. This reduction is due to more porous of RCA and fineness of RHA as compared to cement. Porous media of aggregates has absorbed the water and fineness of RHA powder increased the surface area. Thus, water for imparting the workability has absorbed by aggregates and coats the surface area of RHA which results less slum value.

Table 4. Slump test results

\begin{tabular}{cccc}
\hline Type of concrete & Mix design & W/C ratio & Slump \\
\hline Plain concrete (0\% RA) & $1: 1.5: 3$ & 0.50 & $3.5 \mathrm{in}$ \\
Recycled Concrete (100\% RA) & $1: 1.5: 3$ & 0.50 & $3.25 \mathrm{in}$ \\
Recycled concrete (100\% RA \& 10\% RHA) & $1: 1.5: 3$ & 0.50 & $3.14 \mathrm{in}$ \\
\hline
\end{tabular}

\subsection{Compressive Strength of Concrete}

Compressive strength test is conducted on cubical and cylindrical specimens. This test conducted in UTM machine as shown in Figure 5 by following the standard code i.e. ASTM C39. At each curing age i.e. 7, 14, 21, 28 and 56 days; 3 cubes and 6 cylinders ( 3 for compressive and 3 for splitting tensile strength) were tested and average strength of all specimens was noted. The test results of plain concrete specimens are compared with recycled concrete as given in Figure 6 and 7. The cubical compressive strength of normal, RCA and RCA with 10\% RHA concrete gradually increases with curing time as shown in Figure 6. Beside it, it was found from the experimental analysis that the strength of concrete with RCA has reduced to $23.45 \%$ and with the $10 \%$ RHA concrete increased to $2 \%$ after 7 days curing when compared with normal concrete. Moreover, after 56 days curing time, the concrete with RCA is attained $14.83 \%$ lower strength and RCA with 10\% RHA attained $4.83 \%$ higher strength as compared to concrete with normal aggregates. However, there is $27.6 \%, 42 \%$ and $31.4 \%$ enhanced in cubical compressive strength of normal, RCA and RCA with $10 \%$ RHA concrete respectively at 56 days curing ages when compared with 7 days curing age.

On the other hand, Figure 7 illustrates the cylindrical compressive strength of tested specimens. Exactly similar relation as that of cubical compressive strength has been observed here. Percentage decrease in cylindrical compressive strength of RCA is $27.8 \%$ and increment in strength of RCA with $10 \%$ RHA is $2 \%$ at 7 days. Whilst, these values at 56 days curing age are $22.2 \%$ and $6 \%$. Moreover, at 56 days, the enhancement in cubical strength of normal, RCA and RCA with $10 \%$ of RHA is $42.8 \%, 53.8 \%$ and $48.4 \%$ respectively as compare to early age strength of 7 days.
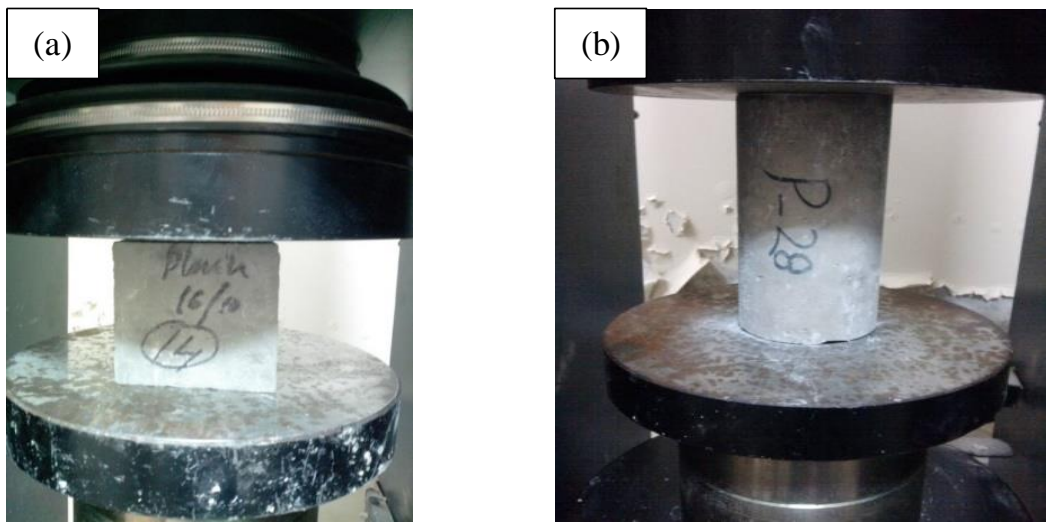

Figure 5. Experimental setup for compressive strength; (a) Cubical test, (b) Cylindrical test 


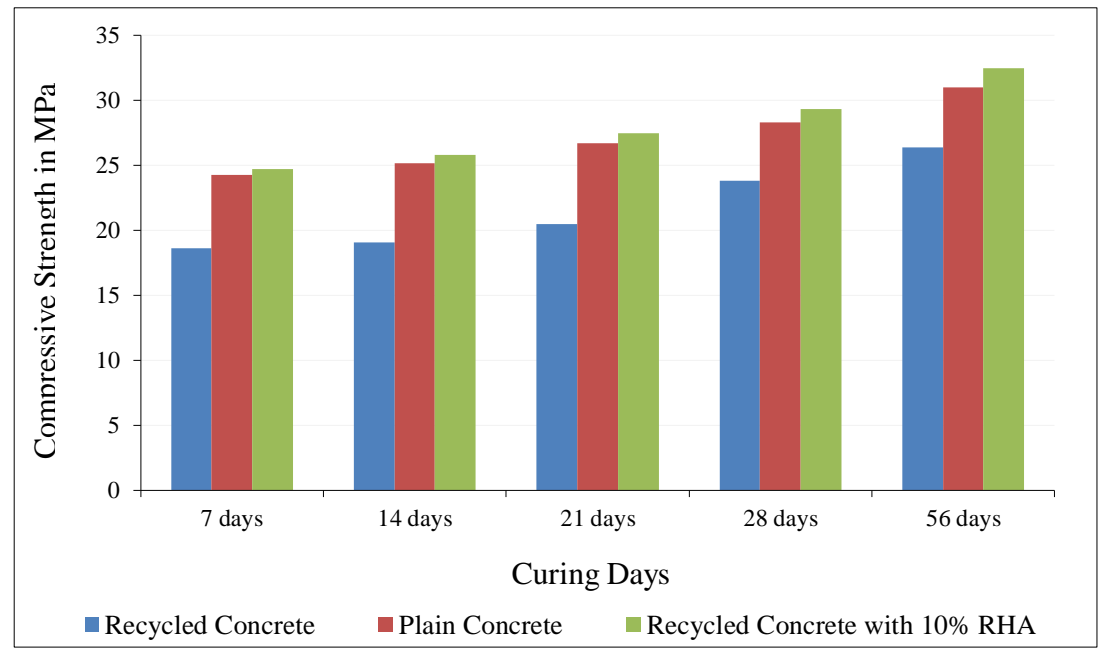

Figure 6. Cubical compressive strength test results

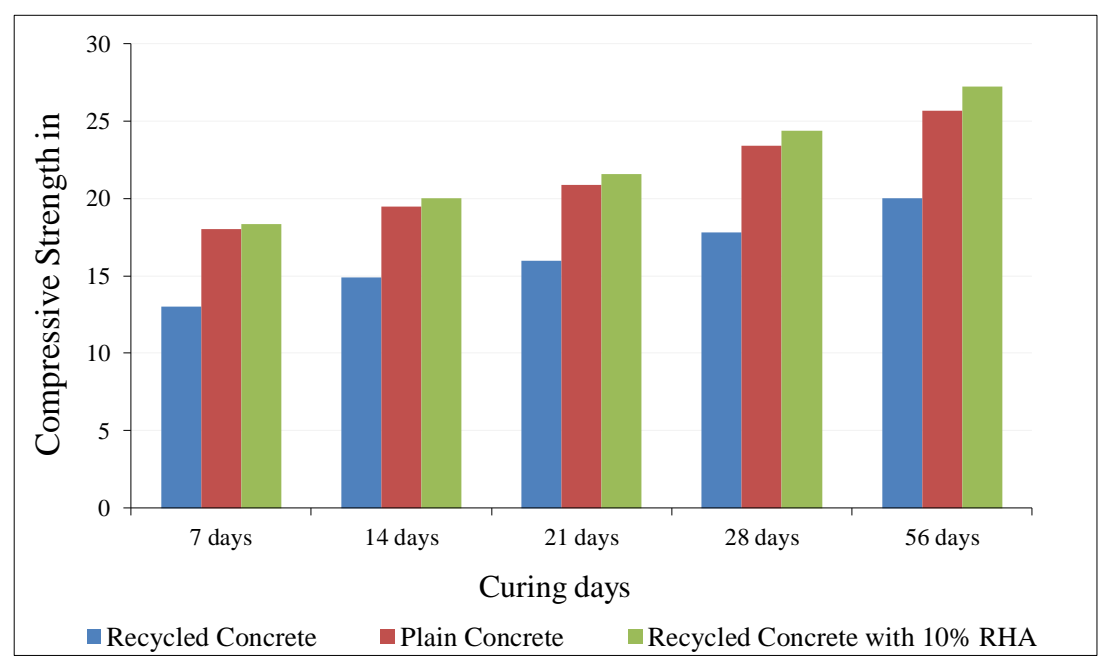

Figure 7. Cylindrical compressive strength test results

\subsection{Tensile Strength of Concrete}

Splitting tensile strength is investigated experimentally in UTM the laboratory testing setup is shown in Figure 8. Total three cylinders were tested at five curing ages. The Figure 9 depicts the graphical representation of variation in tensile strength. Overall, splitting tensile strength arched up throughout course of curing time i.e. 7 to 56 days. Hence a linear behaviour was observed in tensile strength. The strength of RCA concrete plunged at $40.9 \%$ and RCA concrete with $10 \%$ RHA is increased at $2.3 \%$ at 7 days curing period. Likewise, at 56 days, it is lowered at $33.33 \%$ with RCA concrete and enhanced at 4\% with RCA and 10\% RHA concrete, as compared to normal concrete. However, there is $63.6 \%, 84.6 \%$ and $66.2 \%$ increment in tensile strength of normal, RCA and RCA with 10\% RHA concrete respectively at 56 days as compare to 7 days curing age. Thus, with increasing curing ages of RCA concrete with $10 \%$ RHA, the feasible results could be obtained in terms of tensile strength.
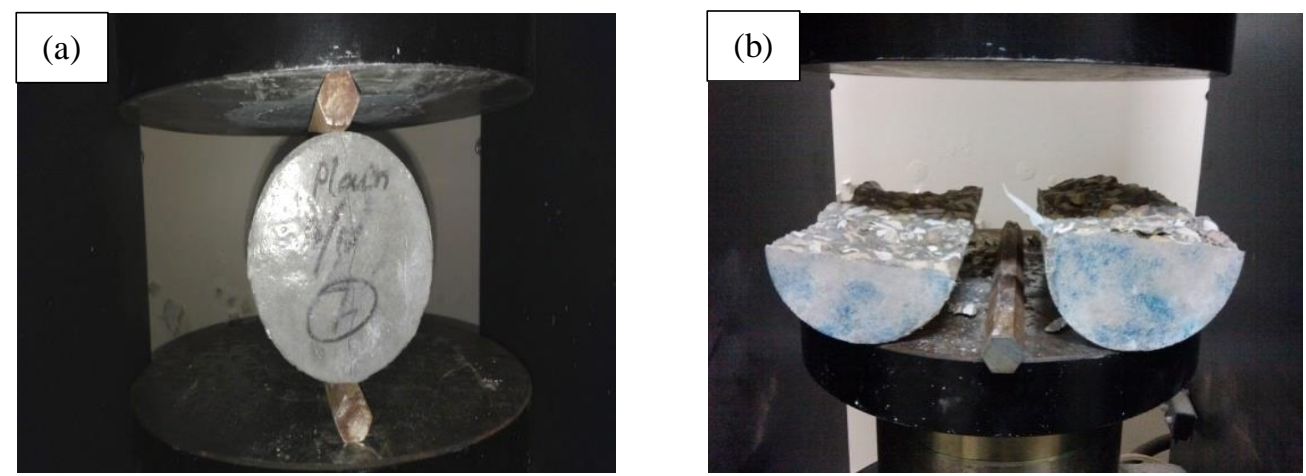

Figure 8. Experimental setup for tensile strength; (a) Before testing, (b) After testing 


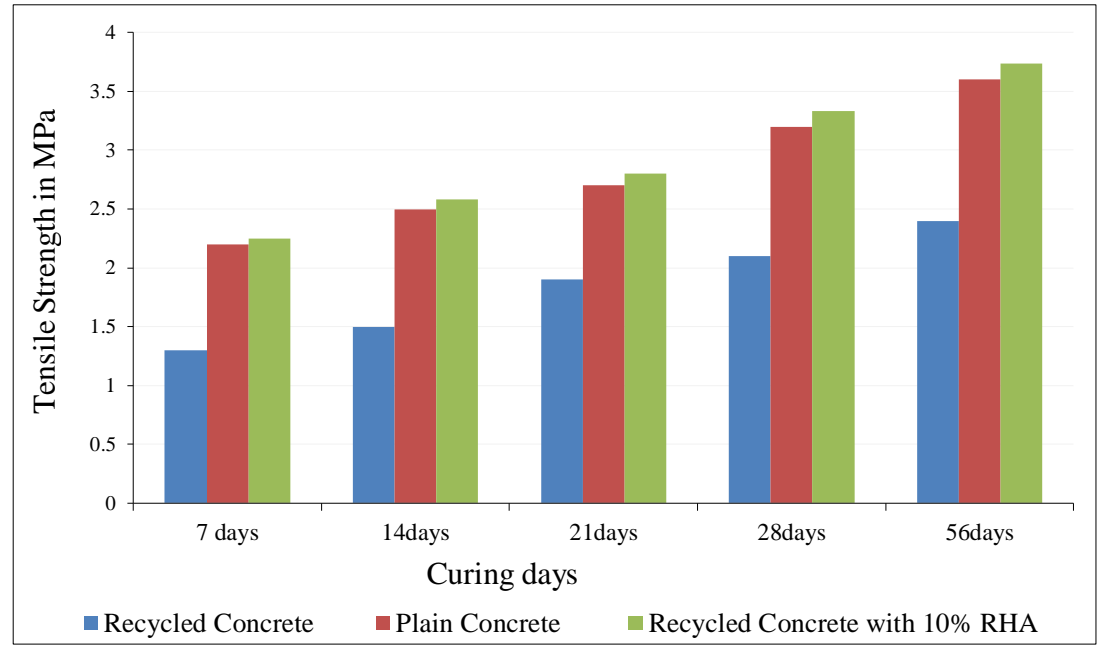

Figure 9. Tensile strength test results

\section{Conclusions}

From detail examination on RCA and RCA with $10 \%$ RHA concrete of 1:1.5:3 mix ratio at 0.50 water-cement ratio, the experimental results can be concluded as:

- RCA with $10 \%$ RHA in fresh concrete can be used for construction site which require higher strength. Thus, such type of concrete not only utilizes the waste but reduce the cost of project also.

- Workability reduced up to $7.7 \%$ and $11.4 \%$ in RCA and RCA with $10 \%$ RHA concrete. Hence the special kind of additive for e.g. plasticizers or superplasticizers should be the part of concrete made up of RCA in future to overcome the resistant in flow of concrete

- Cubical compressive strength is lower when RCA is added. This reduction is higher at 7 days and lower at 56 days curing period. Overall, reduction in strength ranges between 14.83 to $23.45 \%$ when compared with normal concrete.

- Cubical compressive strength is higher when RCA with $10 \%$ of RHA is added. This improvement arched upward as curing age increases and ranges in between $1.8 \%$ to $4.83 \%$ as compare to normal concrete. Hence utilization of RCA only, should be avoided and supplementary material like RHA should be added.

- Cylindrical compressive strength with RCA is plummeted more at lower curing ages than later ages. This reduction ranges between 22.17 to $27.77 \%$ when compare to normal concrete.

- Cylindrical compressive strength of concrete having RCA with $10 \%$ of RHA is increases with curing ages. Generally, it ranges between $2 \%$ to $6 \%$ when compared with normal concrete.

- Splitting tensile strength of concrete with RCA drastically lowered down at earlier age as compared with long curing time. This decrease, as compare to normal concrete, is about $33.33 \%$ to $40.9 \%$. Hence it is not recommended to use RCA for higher demand of tensile stresses in structures.

- Splitting tensile strength of concrete, with RCA and 10\% RHA, is soared at around $2.27 \%$ to $4 \%$ as compare to normal concrete.

From the above conclusion the study strongly recommends the use of RCA with RHA at $10 \%$ by weight. Furthermore, due to the extreme high reduction in tensile strength of concrete, the study recommends another exclusive study on similar research to work out the appropriate size of aggregates, mixing percentages and other supplementary materials to overcome the problem of tensile strength.

\section{References}

[1] Meghwar S.L., Kheskheli G.B., Kumar Aneel, Mahar R.B., "Recycling of Human Scalp Hair as Environmental Friendly Material in Cement Concrete"; In: Harijan, K. ed., Proceedings of the 4th International Conference on Energy, Environment and Sustainable Development, Mehran UET Jamshoro, Sindh, Pakistan: Energy and Environment Engineering Research Group, November 01-03, 2016, Paper ID: EESD_2016_54.

[2] Bestgen JO, Hatipoglu M, Cetin B, Aydilek AH. Mechanical and Environmental Suitability of Recycled Concrete Aggregate as a Highway Base Material. J Mater Civ Eng. 2016;28(9):04016067. doi:10.1061/(ASCE)MT.1943-5533.0001564.

[3] Kang M. Effect of the Aggregate Size on Strength Properties of Recycled. 2018. doi:10.1155/2018/2428576. 
[4] Sharkawi, A. , Almofty, S. and Abbass, E. (2016) Performance of Green Aggregate Produced by Recycling Demolition Construction Wastes (Case Study of Tanta City). Engineering, 8, 52-59. doi: 10.4236/eng.2016.82006.

[5] Lukić I, Malešev M, Radonjanin V, Bulatoví V. Basic properties of structural LWAC based on waste and recycled materials. J Mater Civ Eng. 2017;29(1):1-5. doi:10.1061/(ASCE)MT.1943-5533.0001696.

[6] Anik D, Boonstra C, Mak J. Handbook of sustainable building. James \& James;1996.

[7] Transportation Applications of Recycled Concrete Aggregate-FHWA State of the Practice National Review 2004; U.S. Department of Transportation Federal Highway Administration: Washington, DC, USA, 2004; pp. 1-47.

[8] Eurostat. Waste statistics in Europe. <http://epp.eurostat.ec.europa.eu/> [last accessed June 2013].

[9] S. Al-Otaibi, "Producing lime-silica bricks from crushed concrete fines," in Proceedings of the International Conference on Sustainability in the Cement and Concrete Industry, Lillehammer, Norway, September 2007.

[10] S. Al-Otaibi and M. El-Hawary, A. Abdul-Jaleel "Rrecycling crushed concrete fines to produce lime-silica brick" Waste and Resource Management 163 (2010), Pages 123-127. doi: 10.1680/warm.2010.163.3.123.

[11] Xie T, Ozbakkaloglu T. Behavior of recycled aggregate concrete-filled basalt and carbon FRP tubes. Constr Build Mater. 2016;105:132-143. doi:10.1016/j.conbuildmat.2015.12.068

[12] Carroll JC, Helminger N. Fresh and Hardened Properties of Fiber-Reinforced Rubber Concrete. J Mater Civ Eng. 2016;28(7):04016027. doi:10.1061/(ASCE)MT.1943-5533.0001541.

[13] Ozbakkaloglu T, Gholampour A, Xie T. Mechanical and Durability Properties of Recycled Aggregate Concrete: Effect of Recycled Aggregate Properties and Content. 2018;30(2). doi:10.1061/(ASCE)MT.1943-5533.0002142.

[14] Jianzhuang Xiao, Jiabin Li, Ch. Zhang, "Mechanical properties of recycled aggregate concrete under uniaxial loading". Cement and Concrete Research 35 (2005) 1187- 1194. doi:10.1016/j.cemconres.2004.09.020.

[15] Ramadan y.al Khatib,ahmad A. Khattab and salah a. Taha,Recycling "Construction and Demolition Wastes", Graduation project 1999.

[16] Tam VWY, Wang K, Tam CM. "Assessing relationships among properties of demolished concrete, recycled aggregate and recycled aggregate concrete using regression analysis”. J Hazard Mater 2008;152:703-14. doi:10.1016/j.jhazmat.2007.07.061.

[17] P. Kumar and N. Venugopal, "X-Ray Diffraction Studies of Rice Husk Ash-An Ecofriendly Concrete at Different Temperatures," American Journal of Analytical Chemistry, Vol. 4 No. 8, 2013, pp. 368-372. doi: 10.4236/ajac.2013.48046.

[18] Chandrasekhar, S., Satyanarayana, K.G., Pramada, P.N. et al. "Review processing, properties and applications of reactive silica from rice husk - an overview". Journal of Materials Science (2003) 38: 3159. doi: 10.1023/A:1025157114800.

[19] Nations, F.a.A.O.o.t.U., World paddy production. 2014.

[20] T. G. Chuah, "Rice Husk as a Potentially Low-Cost Bio-sorbent for Heavy Metal and Dye Removal: An Overview", Desalination, vol. 175, no. 3, (2005), pp. 305-316. doi: 10.1016/j.desal.2004.10.014.

[21] Tomas U.Ganiron Jr, “Effect of RH as substitute for fine Aggregate in concrecte mixture” International Journal of Advanced Science and Technology, vol. 58, (2013), pp. 29-40. doi: 10.14257/ijast.2013.58.03.

[22] Malhotra, V.M. and Mehta, P.K. (2004), "Pozzolanic And Cementitious Materials", London: Taylor \& Francis.

[23] J. James and P. K. Pandian, "Industrial wastes as auxiliary additives to cement/lime stabilization of soils," Advances in Civil Engineering, vol. 2016, Article ID 1267391, 17 pages, 2016. doi:10.1155/2016/1267391.

[24] P. N. V. Jayanthi and D. N. Singh, "Utilization of sustainable materials for soil stabilization: state-of-the-art," Advances in Civil Engineering Materials, vol. 5, no. 1, pp. 46-79, 2016. doi: 10.1520/acem20150013.

[25] Kuntikana, Ganaraj, and D. N. Singh. “Contemporary Issues Related to Utilization of Industrial Byproducts.” Advances in Civil Engineering Materials 6, no. 1 (November 1, 2017): 20160050. doi:10.1520/acem20160050.

[26] Jongpradist, Pornkasem, Watee Homtragoon, Raksiri Sukkarak, Warat Kongkitkul, and Pitthaya Jamsawang. "Efficiency of Rice Husk Ash as Cementitious Material in High-Strength Cement-Admixed Clay." Advances in Civil Engineering 2018 (June 21, 2018): 1-11. doi:10.1155/2018/8346319.

[27] Brandes M.R. and Kurma, Y.C. Effect of recycled concrete aggregates on strength and stiffness gain of concrete and on bond strength of steel prestressing strand. PCI Journal | March-April 2018 pp, 87-105H.

[28] Er. Ravi Bhushan, Sopan Gocche, Er. Harneet Singh BPB. Partial replacement of cement by rice husk ash. 2017:251-256.

[29] M. P. Kumar, "Use of Activated Carbons prepared from Sawdust and Rice-husk for Adsorption of Acid Dyes: A Case Study of Acid Yellow 36". Dyes and Pigments, vol. 56, no. 3, (2003), pp. 239-249. doi:10.1016/S0143-7208(02)00159-6.

[30] T. Z. Liou, "Preparation and Characterization of Nano-structured Silica from Rice Husk", Materials Science and Engineering, vol. A 364, no. 1, (2004), pp. 313-323. doi:10.1016/j.msea.2003.08.045.

[31] K. Srinivasan, N. Balasubramanian and T. V. Ramakrishna, "Studies on Chromium Removal by Rice Husk Carbon", Indian Journal of Environmental Health, vol. 30, no. 4, (1988), pp. 376-387.

[32] V. M. Srivastava, I. O. Mall and I. M. Mishra, "Characterization of Mesoporous Rice Husk Ash (RHA) and Adsorption Kinetics 
of Metal Ions from Aqueous Solution onto RHA", Journal of Hazardous Materials, vol. 134, no. 1, (2006), pp. $257-267$. doi:10.1016/j.jhazmat.2005.11.052.

[33] A. H. Mahvi, A. Maleki and A. Eslami, "Potential of Rice Husk and Rice Husk Ash for Phenol Removal in Aqueous Systems", American Journal of Applied Science, vol. 1, no. 4, (2004), pp. 321-326. doi: 10.3844/ajassp.2004.321.326.

[34] EU. DIRECTIVE 2008/98/EC of the European Parliament and the Council of 19 November 2008 on waste and repealing certain Directives. European Union.28 p. doi: 10.1017/cbo9780511610851.024.

[35] Best practice guide for the use of "recycled aggregates in new concrete". Technical report TR 14, Cement \& Concrete Association of New Zealand (CCANZ); October 2011.

[36] Elhakam AA, Mohamed AE, Awad E. Influence of self-healing, mixing method and adding silica fume on mechanical properties of recycled aggregates concrete. Constr Build Mater 2012;35:421-7. doi: 10.1016/j.conbuildmat.2012.04.013. 